\title{
Stretch Hyperreflexia of Triceps Surae Muscles in the Conscious Cat after Dorsolateral Spinal Lesions
}

\author{
J. S. Taylor, R. F. Friedman, J. B. Munson, and C. J. Vierck Jr \\ Department of Neuroscience, University of Florida, Gainesville, Florida 32610-0244
}

Resistive force and electromyograms from triceps surae muscles were measured during dorsiflexion of both ankles of awake cats before and after interruption of one dorsolateral funiculus (DLF). DLF lesions produced ipsilateral increases in dynamic and static reflex force that persisted over 66 weeks. The increase in dynamic reflex force was velocity sensitive, as demonstrated by a greater effect for $60 \% \mathrm{sec}$ than for $10 \% \mathrm{sec}$ dorsiflexion. Also, the lesions increased dynamic force to a greater extent than static force (increased dynamic index). Background force (recorded immediately before each reflex response) was elevated ipsilaterally. However, increases in reflex force were observed when preoperative and postoperative background forces were matched within $10 \%$ and were associated with equivalent resting levels of electromyographic (EMG) activity. Resistive reflex force was significantly correlated with EMG responses to dorsiflexion and was not determined by nonreflexive mechanical stiffness of the muscles. Contralateral background and reflex force and associated EMG activity were decreased slightly, comparing preoperative and postoperative records.

Despite considerable interest in the clinical condition of spasticity, the minimal spinal lesion that produces spasticity has not been identified. Potential reasons for this are: (1) that hyperreflexia is difficult to detect under certain anesthetics or is modified in decerebrate or spinal preparations; (2) that behavioral testing of awake animals has typically involved methods that do not quantitatively evaluate reflex responsivity; (3) that production of spasticity by a given lesion depends on characteristics of spinal pathways that differ between species (e.g., location, size, and terminations); and (4) that an insufficient variety of restricted spinal lesions has been tested thoroughly for effects on segmental reflexes.

A common lesion model for production of hyperreflexia has been lateral hemisection. Using subjective techniques of neurological examination, enduring hyperreflexia has not been confirmed behaviorally after lateral hemisection in some studies (Hultborn and Malmsten, 1983a; Malmsten, 1983; Ashby and McCrea, 1987), but exaggerated tendon jerk reflexes have been observed by others (Teasdall et al., 1965; Fujimori et al., 1966; Murray and Goldberger, 1974; Aoki et al., 1976; Carter et al.,

Received Aug. 19, 1996; revised April 9, 1997; accepted April 21, 1997.

This work was supported by National Institutes of Health Grants NS 15913, NS 27511, and NS 35702 and by funds from the Brain and Spinal Cord Injury Rehabilitation Trust Fund from the state of Florida. The technical support of Carolyn Baum and Boza Radisavljevic is gratefully acknowledged.

Correspondence should be addressed to Dr. C. J. Vierck, Department of Neuroscience, University of Florida College of Medicine, Gainesville, FL 32610-0244.

Copyright (C) 1997 Society for Neuroscience $0270-6474 / 97 / 175004-12 \$ 05.00 / 0$
Clinical testing revealed ipsilateral postoperative increases in extensor tone, increased resistance to hindlimb flexion, hypermetria during positive support responses, and appearance of the Babinski reflex. However, the most reliable tests of DLF lesion effects were the quantitative measures of dynamic and static reflex amplitude. The enhancement of stretch reflexes is suggestive of spasticity. However, hyperactive stretch reflexes, hypertonicity, and the Babinski reflex were observed soon after interruption of the ipsilateral DLF, in contrast to a gradual development of positive signs that is characteristic of a more broadly defined spastic syndrome from large spinal lesions. Also, other signs that often are included in the spastic syndrome, including clonus, increased flexor reflex activity, and flexor spasms, did not result from DLF lesions. Thus, unilateral DLF lesions provide a model of spasticity but produce only several components of a more inclusive spastic syndrome.

Key words: stretch reflex; spinal cord injury; cat; soleus; gastrocnemius; spasticity

1991). Using this model, asymmetry of reflexes ipsilateral and contralateral to lateral hemisection has been regarded as evidence of spasticity (Hultborn and Malmsten, 1983b), but comparisons with normal (preoperative) reflexes are needed to ensure that bilateral effects are not produced. For example, interruption of a ventral spinal quadrant in primates produces a depression of flexion reflexes that is greater contralaterally (Vierck et al., 1990; Garcia-Larrea et al., 1993), producing a false impression of ipsilateral hyperreflexia (in comparison with the contralateral limb postoperatively). Another contributing factor for the lateral hemisection model is that proximity of the lesion to the tested reflex circuitry can enhance the probability that hyperreflexia is seen (Nelson and Mendell, 1979; Carter et al., 1991). However, clinical spasticity can be produced by lesions at all levels of the neuraxis (Brown, 1994). Therefore, hyperreflexia in an appropriate animal model of spasticity should not be difficult to detect or be dependent on the distance of a lesion from the segments tested (Little, 1986).

An alternative model of spasticity interrupts dorsal pathways and avoids inclusion of the ventral spinal quadrant. In contrast to the hyporeflexia from ventral lesions (Vierck, 1991; Nathan, 1994), unilateral interruption of the dorsolateral funiculus in decerebrate (Burke et al., 1972) or spinal (Cavallari and Pettersson, 1989) cats and more extensive dorsal hemisections in decerebrate cats (Rymer et al., 1979) have produced evidence for hyperreflexia (and the clasp-knife phenomenon; Heckman, 1994). However, demonstration of these effects with quantitative evalu- 
A. B.
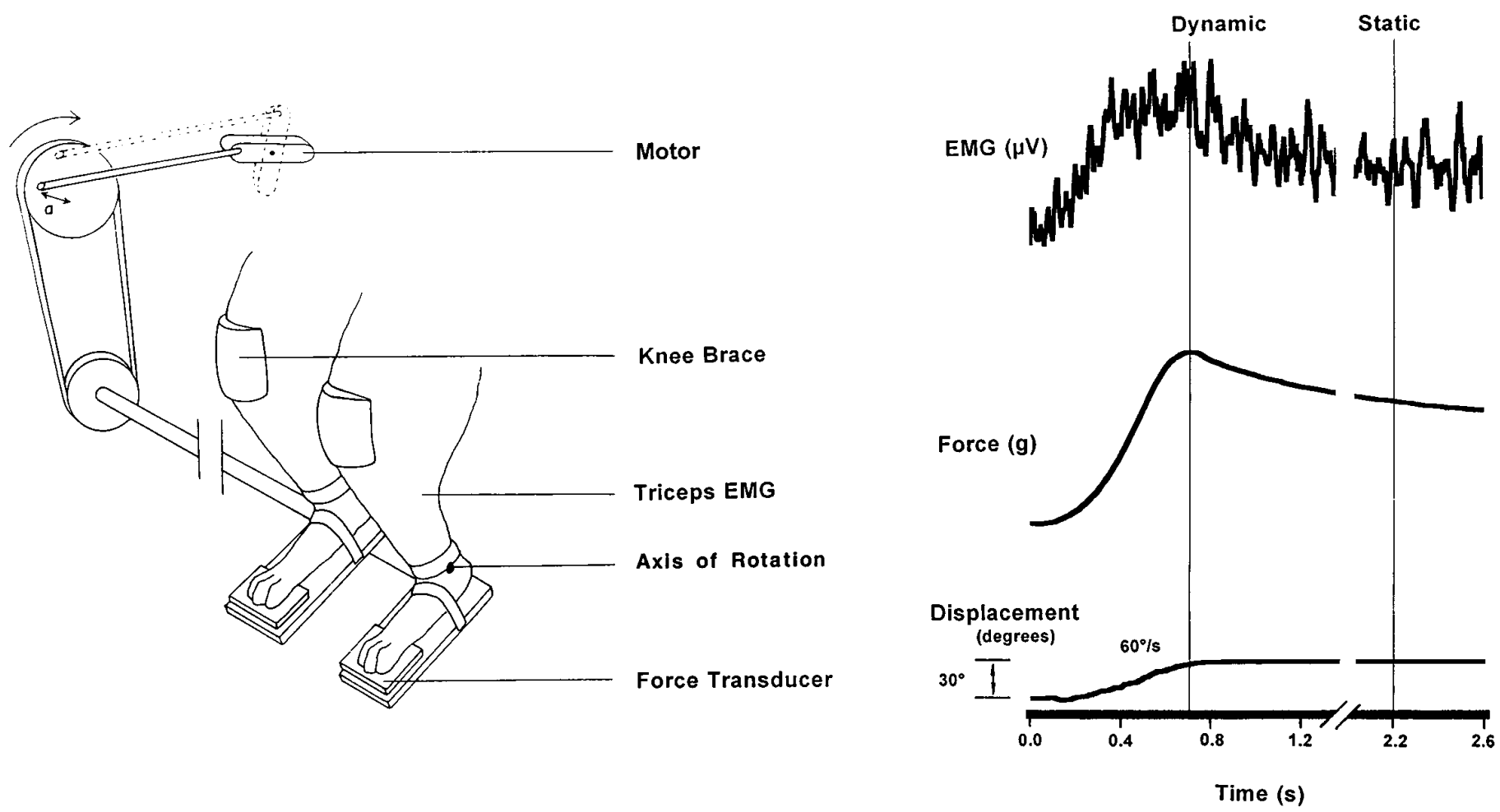

Figure 1. A, Schematic diagram of the apparatus used to evoke stretch reflex activity in the conscious cat. Reflex EMG and force activity were evoked by ramp and hold dorsiflexion of both feet by a DC motor. $B$, Sample displacement of the ankle and EMG and force responses to a $30^{\circ}$ dorsiflexion of the foot at $60^{\circ} / \mathrm{sec}$ are shown for one limb. Cursor positions for determination of dynamic and static amplitude are shown.

ations of preoperative and postoperative reflex strength in awake animals is needed. To evaluate whether the dorsolateral lesion model has characteristics that define spasticity (Lance, 1980; Thilmann, 1993), the testing methods must provide control over the amplitude and velocity of muscle stretch, and the initial operating conditions must be standardized (Katz and Rymer, 1989; Miller, 1993). Reflex strength should be evaluated in relation to initial resting or background force levels (Lee et al., 1987; Hoffer et al., 1990) and should be related to muscular activity.

In the present study, dynamic and static stretch reflex measures were derived from resistive force and electromyographic (EMG) recordings from the soleus (SOL) and gastrocnemius medialis (MG) muscles. Reflex responses to different velocities and extents of ramp and hold dorsiflexion at the ankle were compared. The initial load on the stretched muscles was monitored and was matched in a post hoc comparison of preoperative and postoperative reflexes. To evaluate whether reflex alterations developed quickly or slowly and were transient or maintained, reflexes were monitored up to 66 weeks after dorsolateral spinal lesions. The contribution of EMG activity from the SOL and MG muscle groups to force output was assessed by correlational analysis. Clinical assessments of hindlimb tone and reflexes were performed in parallel with the quantitative reflex tests.

\section{MATERIALS AND METHODS}

Six adult female cats, weighing between 3 and $5 \mathrm{~kg}$, were selected for sociability and toleration of restraint and hindlimb manipulation. Four of the animals were spayed. The animals were individually housed in large cages and were treated in accord with National Institutes of Health guidelines (National Institutes of Health, 1991). Research protocols were approved by the University of Florida Institutional Animal Care and Use Committee. The cats were trained over 3-5 months to accept restraint and flexion/extension movements at the ankles. One technician trained and tested all the animals, reducing a source of variability. The animals were fed to satiation once daily, either during or after a testing session or at approximately the same time on other days.

\section{Stretch reflex apparatus}

Triceps surae stretch reflexes were elicited by simultaneously and equally dorsiflexing both hindpaws (Fig. 1). The animals were comfortably suspended in a sling that wrapped around the torso. A continuous low flow of liquid food was provided during the testing sessions. A molded saddle supported the hindquarters, and the forepaws were supported on a platform. The cats were trained to accept placement of both hindpaws into "boot" platforms, with Velcro and elastic straps securing the dorsal surface and the calcaneum of the foot within the boot. Movement of the boot was translated primarily to the ankle, and displacement of the knee joints was minimized by placement of a brace over each knee (Fig. 1).

Oscillation of the boots was produced by a DC motor, working through adjustable cogs and a flywheel (Fig. 1) that specified the initial foot-tibia angle and the degree of displacement $\left(20-43^{\circ}\right)$. The DC motor was controlled by an analog circuit that dictated the speed of displacement (from 10 to $60^{\circ} / \mathrm{sec}$ ) and the hold duration (set at $4 \mathrm{sec}$ ). The reactive torque produced by the plantar-flexor moment at the ankles was monitored from force transducers (Entran) located beneath two "paddles" under the toe pads of both hindpaws. The distance from both force transducers to the axis of the ankle joint was $6.5 \mathrm{~cm}$.

\section{EMG electrode implantation}

After the training procedure, the cats were surgically prepared for sterile implantation of bipolar EMG electrodes. The animals were deeply anesthetized with halothane in a mixture of 3:1 nitrous oxide and oxygen and 
were administered an antibiotic. Bipolar electrodes were made from seven-stranded, Teflon-coated, stainless steel wire (Biomed wire, Cooner), exposed at the tip over 1-2 mm, with the two electrodes placed $1 \mathrm{~cm}$ apart. Electrodes were placed deep inside the belly of the MG and SOL muscles (Loeb and Gans, 1986) and were sutured to the muscle fascia. The wires were brought to a 12 pin connector (Microtech Inc.) mounted in a stainless steel ring. The ring was secured to the wing of each iliac crest with orthopaedic wire, and the skin was reapposed around the mount. Daily care of the skin surrounding the ring involved cleaning the area with a weak solution of hydrogen peroxide, followed by application of antibiotic ointment (e.g., Neosporin). Reflex testing was resumed after a rest period of 2 weeks after electrode implantation. EMG electrode insertion into the belly of the appropriate muscle was confirmed after the study.

\section{Experimental protocol}

The ankle joint was flexed 20,30 , or $43^{\circ}$ from neutral positions of $120^{\circ}$ or $143^{\circ}$ between the tibia and the foot. The angle at the knee was maintained at $130-140^{\circ}$. The rate of displacement was generally $60^{\circ} / \mathrm{sec}$, but ramps of $10^{\circ} / \mathrm{sec}$ were included for $30^{\circ}$ perturbations to assess the velocity sensitivity of the reflex responses. To compensate for possible effects of the lesions on resting force, preoperative and postoperative reflex responses were compared by matching trials on the basis of initial background forces.

\section{Surgical procedures and postoperative care}

After collection of stable baseline data, selective lesions of the spinal cord were made under fully sterile conditions. Deep surgical anesthesia was induced and maintained with halothane, $1-3 \%$ in a $3: 1$ nitrous oxide-tooxygen mixture. The appropriate vertebrae were exposed, followed by a small $(1 \mathrm{~cm})$ dorsal hemilaminectomy. Two cats received a dorsolateral funiculus (DLF) lesion at the L4 vertebral level, and four cats received this lesion at levels ranging from T13 to L3. The lesions extended 1-2 mm in the rostrocaudal dimension, except for one lesion cavity that was 4-5 $\mathrm{mm}$ in length (cat 5). The dura was closed with 9-0 suture, and the wound was closed in layers.

The cats showed no signs of discomfort and were only minimally disadvantaged by the limited spinal lesions. Bowel and bladder function recovered within the first or second postoperative day; manual expression of the bladder was applied twice daily until that time. Mobility was reduced for 1-4 d but recovered almost completely, with few signs of deficits in hindlimb locomotor ability. The cats were observed to jump, run, and play normally. The animals were retested no earlier than 1 week after surgery and were studied for 26-66 weeks. The extent and level of each lesion were confirmed by postmortem inspection of cell- and fiberstained histological sections (Fig. 2).

\section{Data collection}

EMG activity was filtered $(3-500 \mathrm{~Hz})$ and amplified by a Grass polygraph, with recording of calibration signals before each animal was tested. Analog data were converted to digital recordings via an analog-to-digital converter (eight channels, $0-1475 \mathrm{~Hz}$ ) and stored on VHS tape.

\section{Post hoc digital analysis and statistical testing}

Off-line analysis of force and EMG activity was performed using software written in Borland $\mathrm{C}^{++}$and run on a personal computer. The EMG signals were rectified and filtered by sampling at $33 \mathrm{~Hz}$, after ensemble averaging of six trials. Initial background, dynamic, and static amplitudes were calculated from both the EMG and force records. Initial background levels were determined during a $100 \mathrm{msec}$ period at the onset of each perturbation of the ankle. Dynamic amplitudes were measured as the peak response, and static amplitude was measured at $1.5 \mathrm{sec}$ after ramp termination. Total EMG activity was calculated by summing responses from the SOL and MG muscles over the designated period.

\section{Clinical assessment}

Each of four cats was tested weekly with a battery of subjective tests designed to assess hindlimb tone and reflexes before and after a spinal lesion at T13-L3. The clinical assessments were performed for both hindlimbs by the same individual to avoid interexaminer variation.

Resistance to passive flexion and extension at the ankle, knee, and hip joints was assessed with a scale originally developed by Bohannon and Smith (1987) but referred to as a modified Ashworth scale (Ashworth, 1964). The animal was suspended in air and supported under the fore-

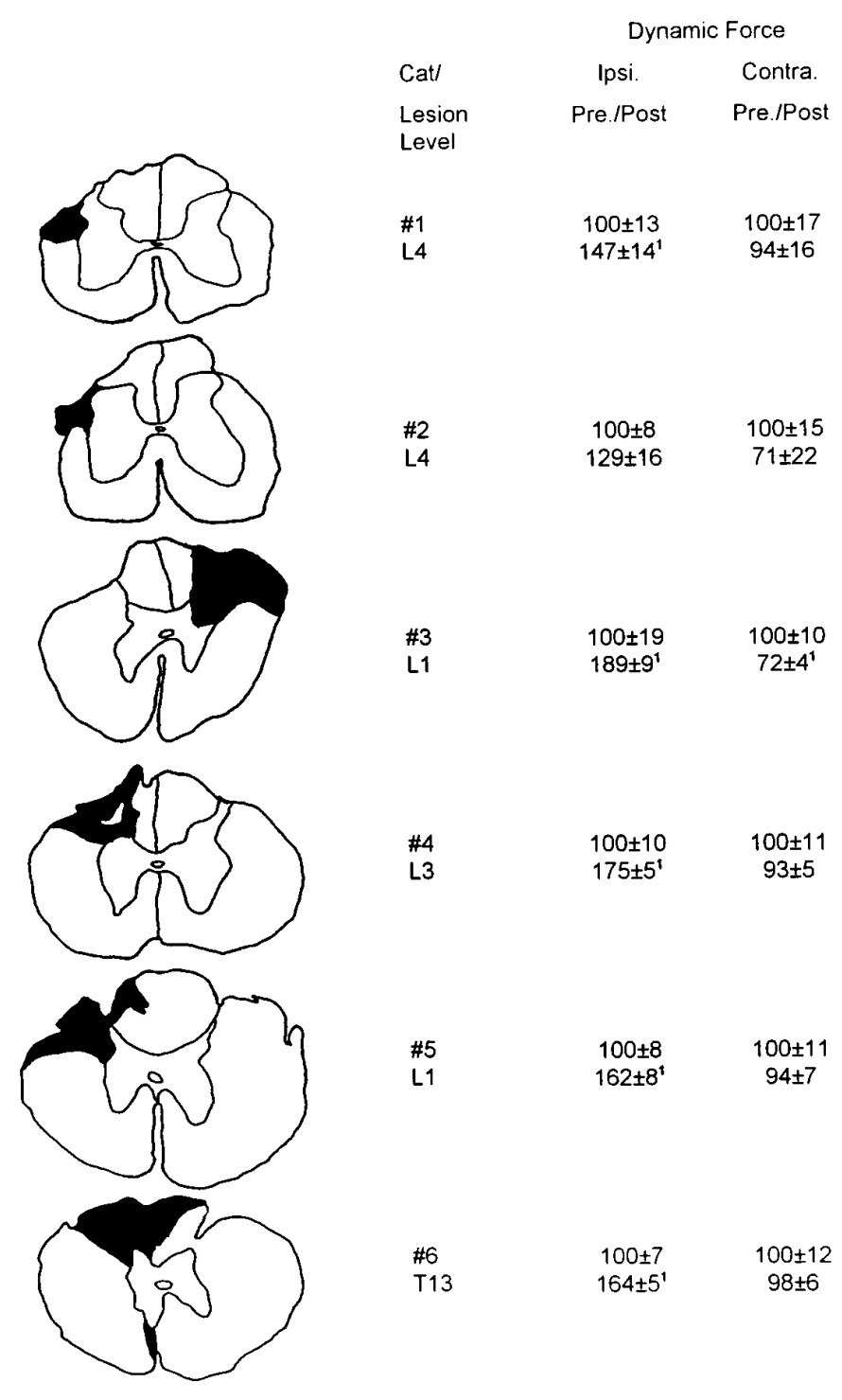

Figure 2. Transverse spinal sections illustrating the location and extent of the spinal lesions and the postoperative amplitudes of dynamic force, averaged from responses obtained with $30^{\circ}$ displacement at $60^{\circ} / \mathrm{sec}$ and normalized to the preoperative value for each hindlimb. Results of L4 DLF lesions (\#1, \#2) were averaged over 6 weeks, and the effects of T13-L3 DLF lesions (\#3-\#6) were averaged over 26 postoperative weeks (means \pm SE). Reflexes were evoked from a $143^{\circ}$ foot-tibial angle for L4 DLF lesions and $120^{\circ}$ for T13-L3 DLF lesions. All cats except cat 2 showed a significant ipsilateral increase in dynamic force postoperatively. Cat 3 revealed a significant decrease in contralateral reflex amplitude, postoperatively. ${ }^{1}$ Two-tailed $t$ tests, $p<0.05$; \#1, \#2, df $=11$; \#3-\#6, df $=28$.

limbs by a technician as the investigator produced rotation at each joint with one hand and provided proximal restraint with the other hand. An ordinal rating scale was used to classify tone as: 0 , no increase in tone during flexion and extension; 1, slight increase in tone, manifested by a catch and release or by minimal resistance at maximal flexion or extension; 2, slightly increased tone, manifested by a catch, followed by minimal resistance throughout the remainder (less than half) of the range of motion; 3 , increased tone through most of the range of motion, but movement is produced easily; 4, considerable increase in tone, and passive movement is difficult; and 5, rigidity in flexion or extension.

Extensor tone was assessed also using a scale developed by us. The animal was suspended under the forelimbs, with the back resting against the chest of the technician. The resting posture of each hindlimb was assessed by ordinal scaling as: 1, flexion at both the knee and ankle joints; 
2, flexion at the knee joint only; 3 , extension at the knee joint only; and 4 , extension at the knee and ankle joints. Extensor tone was assessed further by simultaneously flexing both hindlimbs 10 times, exerting moderate pressure against both plantar pads. The postural state of both hindlimbs during exertion of flexor force by the investigator was assessed using the ordinal scale described above.

Babinski sign and reflex. The animal was suspended in air with the hindlimbs presented toward the investigator. The presence of a tonic Babinski sign was scored as 1 if a clear separation of all the digits of the foot was noted or 0 for no separation. To test for an evoked Babinski reflex, the knee and ankle joint were held firmly in place, and the forefinger was used to apply a moderate stroking force to the plantar surface. Observation of a separation of the toes was scored as 1 , and no response was scored as 0 .

Positive support reaction. The positive support reaction was tested by supporting the cat under the forelimbs, covering the eyes to prevent visual cues, and gently lowering the animal so that both hindpaws made simultaneous contact with the surface of a table. Responses of each hindlimb to maintain weight support were categorized as: 1, weakness in retracting the hindlimb after surface contact; 2 , coordinated retraction of the hindlimb to assume weight support; and 3, a dysmetric response of the hindlimb, usually evident as hypermetric extension. In addition, the positive support reaction was videotaped from one side, so that the final position of the hindlimbs could be analyzed. This postural response of the affected limb was assessed by measuring the distance between the leading edge of the toes of the ipsilateral and contralateral limbs using a calibrated checkered background.

Clonus and tendon reflexes. A test for clonus involved rapid dorsiflexion of the foot while the ankle joint was held rigid. Clonic responses of greater than two to three beats were graded as 1 . Tendon reflexes were investigated by gently tapping the Achilles tendon while the animal rested in a supine position. However, a high degree of variability was associated with this test, and the results are not presented.

\section{Statistical analysis}

Statistical analyses of stretch reflex data were performed using paired and unpaired $t$ tests and ANOVA. Correlation coefficients and linear regressions were obtained with CSS-Statistica software, as were analyses of the results of clinical assessment with nonparametric tests: the Mann-Whitney $U$ test, Spearman rank correlation, and item analysis.

\section{RESULTS}

\section{The magnitude and time course of changes in reflex force after DLF lesions}

Small lesions of the DLF at L4 (animals 1 and 2) resulted in a modest increase in ipsilateral reflex force (Figs. 2, 3A, 4A). Analyzed for trials involving $30^{\circ}$ dorsiflexion at $60^{\circ} / \mathrm{sec}$, dynamic and static forces for these animals were enhanced to 135 and $149 \%$, respectively, of preoperative values during the first 6 weeks of postoperative testing [Table 1 ; dynamic, $F_{(1,9)}=9.97 ; p=0.01$; static, $\left.F_{(1,9)}=10.20 ; p=0.01\right]$, and then reflex force decreased to levels at or below control (Fig. 4A). Slightly more extensive interruption of the DLF at T13-L3 plus damage to the dorsal column laterally (animals 3-6; Figs. 2, 3B, 4B) produced a substantial increase in ipsilateral reflex amplitude. Enhancements of dynamic and static force were to 171 and $173 \%$, respectively, of preoperative control values over 26-66 weeks of postoperative testing [Fig. $4 B$, Table 1; dynamic, $F_{(1,32)}=83.63 ; p<0.001$; static, $\left.F_{(1,30)}=78.00 ; p<0.001\right]$. Lesions on the right side of the cord (animal 3 ) or on the left (all other animals) were associated with ipsilateral hyperreflexia, demonstrating that methodological bias was not introduced by the testing apparatus. Contralaterally, dynamic and static force were decreased postoperatively, but these effects were not statistically significant for L4 or T13-L3 lesions (Table 1).

\section{Hyperreflexia in relation to angular displacement and initial background force}

For displacements of the ankle joint of $>20,30$, and $43^{\circ}$ from $120^{\circ}$, normalized curves were constructed to illustrate the input-output
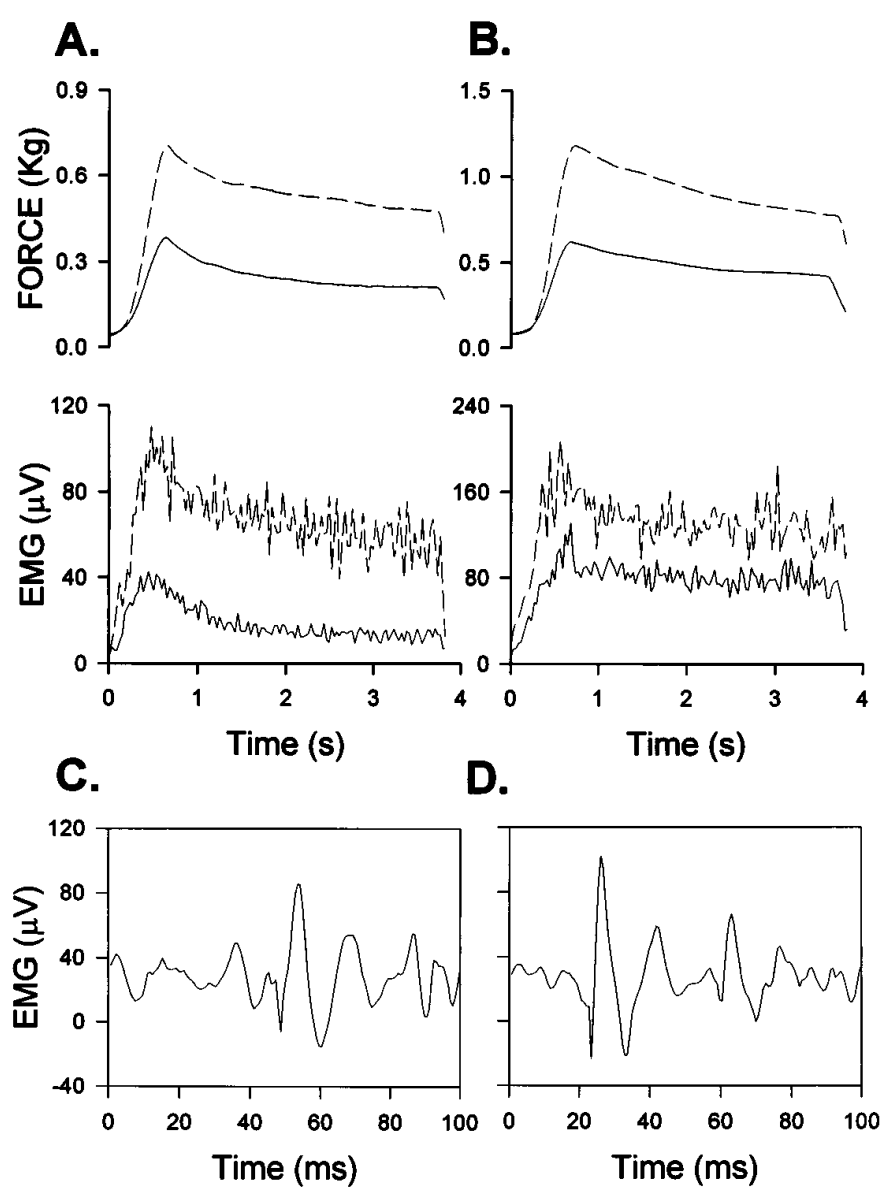

Figure 3. Stretch reflex records showing ipsilateral force and EMG responses to dorsiflexion $(A, B)$ and background EMG activity after DLF lesions $(C, D)$. Averaged rectified $\mathrm{MG}$ activity and force are shown during $30^{\circ}$ displacements at $60^{\circ} / \mathrm{sec}$ from a foot-tibial angle of either $143^{\circ}(\mathrm{A}$, cat 1 at 6 weeks postlesion) or $120^{\circ}$ (B, cat 6 at 9 weeks postlesion). Solid lines represent preoperative responses, and broken lines represent postoperative responses from closely matched background forces. Both dynamic and static reflex amplitudes were increased by the DLF lesions. Background SOL activity obtained before $30^{\circ}$ displacements at $60^{\circ} / \mathrm{sec}$ at a foot-tibial angle of $120^{\circ} 1$ week before $(C)$ and 5 weeks after $(D)$ a DLF lesion (cat 3 , activity displayed at a sampling rate of $1475 \mathrm{~Hz}$ ).

functions for dynamic and static reflex amplitude, before and after T13-L3 lesions (Fig. 5). ANOVA revealed significant postoperative elevations for ipsilateral dynamic force $\left[F_{(1,22)}=8.35 ; p=\right.$ $0.009]$ and static force $\left[F_{(1,2)}=8.25 ; p=0.009\right]$ over the three tested angles compared with preoperative values.

The preoperative background forces at the neutral foot-tibial angle of $120^{\circ}$ were low compared with the range of background forces observed by Hoffer et al. (1990) in normal cats. However, extensor reflexes can be elicited readily from low levels of resting force and contraction (Hoffer et al., 1990; Toft et al., 1991). Postoperatively, contralateral background force was decreased, but insignificantly (Table 1). In contrast, ipsilateral background force was significantly increased by T13-L3 lesions [Table 1; $\left.F_{(1,30)}=18.00 ; p<0.001\right]$. Therefore, post hoc tests of ipsilateral reflex responses from comparable levels of background force were conducted for each animal. Using prelesion and postlesion trials with background forces that were matched within $10 \%$ (Fig. 6), the effects of DLF lesions on reflex force were similar to the results obtained with unmatched background forces (Table 1). No significant postoperative increase in either dynamic or static force 


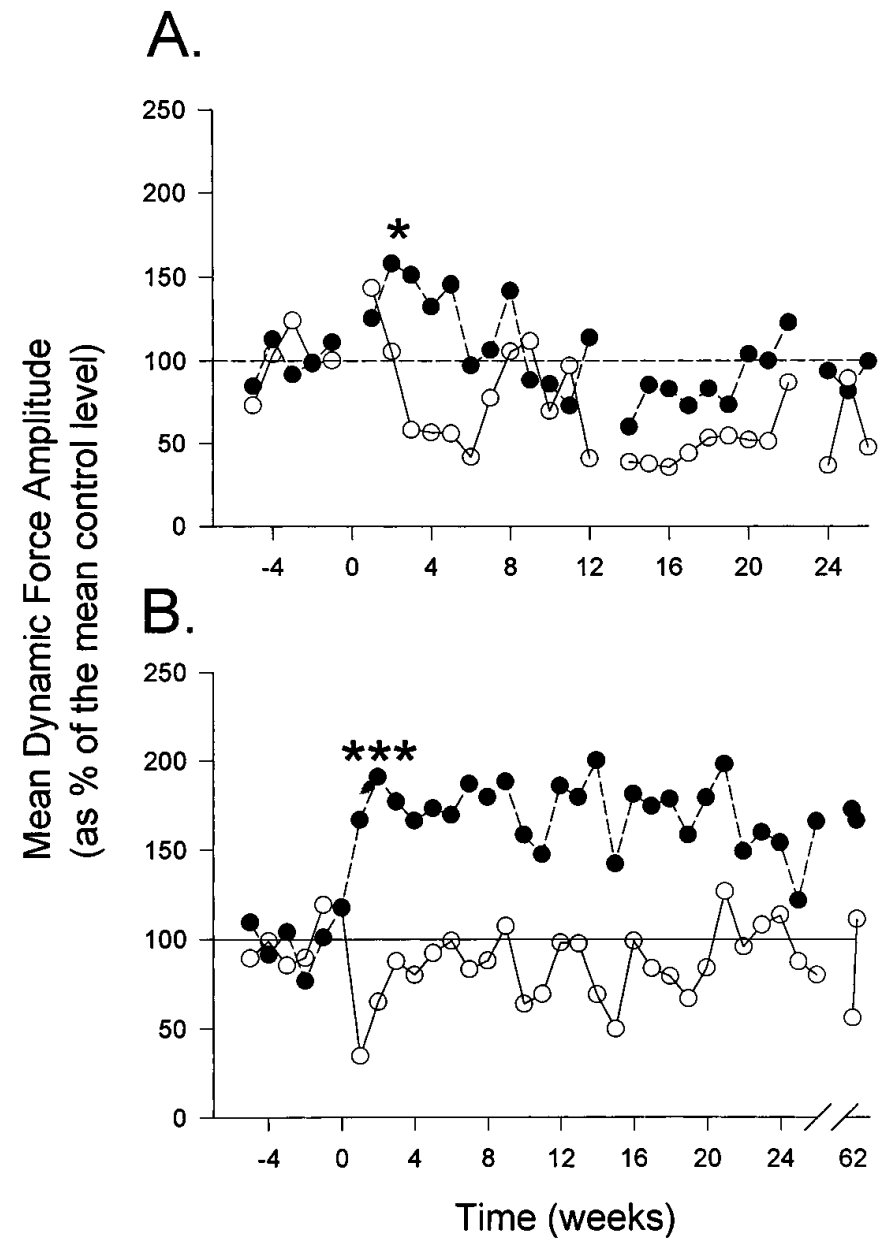

Figure 4. Longitudinal analysis of averaged dynamic force before and after L4 lesions $(A, n=2)$ and T13-L3 lesions of the DLF $(B, n=4)$. Reflexes evoked using a $30^{\circ}$ displacement at $60^{\circ} / \mathrm{sec}$ from a foot-tibial angle of either $143^{\circ}(A)$ or $120^{\circ}(B)$. Filled circles represent the ipsilateral stretch reflex, and open circles represent the contralateral response. DLF lesions at L4 produced a transient facilitation of ipsilateral reflexes $\left({ }^{*} p<\right.$ $0.05)$, which returned to control levels beyond 6 weeks postlesion. T13-L3 lesions produced a statistically significant ipsilateral hyperreflexia $(* * * p<$ 0.001 ) that was maintained for up to 66 weeks postlesion. [L4, $F_{(1,9)}=$ 10.0; T13-L3, $\left.F_{(1,32)}=83.6\right]$. The contralateral reflex depression was evaluated over 6 postoperative weeks and was not significant for either group.

was produced by L4 lesions [dynamic, $F_{(1,10)}=2.59 ; p=0.14$; static, $\left.F_{(1,10)}=2.26 ; p=0.16\right]$, but T13-L3 lesions significantly elevated both dynamic and static force [dynamic, $F_{(1,18)}=10.17$; $p=0.004$; static, $F_{(1,28)}=7.92 ; p=0.009$ ] on trials with matched background force.

\section{Reflex EMG changes after T13-L3 DLF lesions}

A postoperative increase in dynamic SOL activity, to $139 \pm 8 \%$ of preoperative values, was obtained ipsilateral to the T13-L3 lesions $\left[F_{(1,20)}=7.9 ; p=0.01\right]$. Dynamic $\mathrm{MG}$ activity also was increased ipsilaterally, but this effect was not significant [124 \pm $\left.17 \% ; F_{(1,19)}=0.71 ; p=0.41\right]$. T13-L3 lesions produced a significant decrease in contralateral dynamic responses of $\mathrm{MG}$ over 3 months of postoperative testing, to $81 \pm 4 \%$ of preoperative values $\left[F_{(1,16)}=17.54 ; p=0.0007\right]$. This contralateral decrease was specific to the MG muscle, because no significant change was observed for contralateral SOL responses $[93 \pm 12 \%$ of prelesion values; $\left.F_{(1,20)}=0.75 ; p=0.40\right]$.

\section{Relationships between force and EMG activity}

Before and after T13-L3 lesions, resting EMG activity for trials with matched background forces was comparable for SOL (17 \pm 2 and $13 \pm 2 \mu \mathrm{V})$ and $\mathrm{MG}(17 \pm 2$ and $15 \pm 2 \mu \mathrm{V})$. Also, the mean preoperative ratio of dynamic reflex force to total EMG activity $(4 \pm 0 \mathrm{gm} / \mu \mathrm{V})$ was equal to the postoperative ratio ( $4 \pm$ $0 \mathrm{gm} / \mu \mathrm{V})$. In an additional analysis, correlations of force measurements with MG, SOL, and total EMG activity were computed for the animals with T13-L3 lesions (Table 2). Background, dynamic, and static force correlated significantly with MG, SOL, and total EMG activity levels in the preoperative period. Ipsilateral DLF lesions enhanced the correlations of dynamic and static force with MG and total EMG activity, but correlations with SOL activity were not increased beyond preoperative levels.

\section{Velocity sensitivity and dynamic index for reflex force}

Case studies of dynamic reflex force at $60 \% \mathrm{sec}$ relative to responses obtained at $10^{\circ} / \mathrm{sec}$ are shown for cats 3-6, with DLF lesions at T13-L3 (Fig. 7). Significant postoperative increases in velocity sensitivity were observed for cats 3,5 , and 6 . Changes in ipsilateral dynamic reflex force as a function of velocity for the groups of animals with DLF lesions are shown in Figure $8 B$. The difference in mean dynamic amplitude evoked by displacements of $30^{\circ}$ at 60 and $10^{\circ} \mathrm{deg} / \mathrm{sec}$ was $54 \pm 16$ preoperatively and $107 \pm$ $13 \mathrm{gm}$ postoperatively for a 26 week period after DLF lesions at T13-L3 $\left[F_{(1,30)}=8.04 ; p=0.0081\right]$. The effect of velocity was evident from SOL recordings $\left[0.1 \pm 1.7-9.3 \pm 1.5 \mu \mathrm{V} ; F_{(1,20)}=\right.$ $11.5 ; p=0.0029]$ but not for the MG muscle [5 $\pm 2-11 \pm 2 \mu \mathrm{V}$; $\left.F_{(1,19)}=3.10 ; p=0.0942\right]$. Background SOL activity was routinely observed before $(18 \pm 1 \mu \mathrm{V})$ and after DLF lesions $(17 \pm 1 \mu \mathrm{V}$; Fig. $3 C, D)$, and the velocity sensitivity of dynamic reflex force was not significantly related to levels of background SOL activity $(r=$ $0.268 ; p=0.31$ ). That is, the velocity sensitivity was not dependent on resting levels of motoneuronal activation.

The dynamic index (dynamic minus static response amplitude) for ipsilateral force was increased following T13-L3 lesions (Fig. $8 A)$, from $108 \pm 10$ to $156 \pm 9 \operatorname{gm}\left[F_{(1,30)}=11.2 ; p=0.0022\right]$. When postoperative background force levels were matched within $10 \%$ of preoperative control levels, increases in velocity sensitivity from $165 \pm 13$ to $252 \pm 14 \mathrm{gm}\left[F_{(1,28)}=11.9 ; p=0.0018\right]$ and dynamic index from $123 \pm 12$ to $226 \pm 21 \mathrm{gm}\left[F_{(1,28)}=9.46 ; p=\right.$ $0.0047]$ were also observed. In contrast to the effects of T13-L3 lesions, the velocity-dependent difference in reflex force for L4 lesions was $44 \pm 24 \mathrm{gm}$ preoperatively and $27 \pm 16$ gm over 6 postoperative weeks. The preoperative dynamic index was $112 \pm$ 15 gm for animals receiving L4 lesions compared with $118 \pm 12$ gm postoperatively.

\section{Clinical assessments}

Very few postoperative deficits were observed when the animals performed normal behavioral routines such as walking, running, or jumping. However, spinal lesions at T13-L3 produced significant changes on several clinical tests of hindlimb functions (Table $3)$. Postoperative increases in the Ashworth score for ipsilateral ankle flexion (1.3-2.1) and knee flexion (1.2-2.0) indicated that T13-L3 spinal lesions produced a slight increase in tone for the triceps surae muscle group. However, tests of hindlimb posture and resistance to flexion of the hindlimb demonstrated a substantial increase in ipsilateral tone. Preoperatively, both hindlimbs were maintained in an extensor posture when the animals were suspended. Postoperatively, the resting posture during suspension was asymmetric, with the ipsilateral limb extended and the con- 
Table 1. Mean reflex force (in grams) measured before and after unilateral lesions of the DLF at T13-L3 ( $n=4$; 6 months postlesion) or at L4 $(n=2 ; 6$ weeks postlesion)

\begin{tabular}{|c|c|c|c|c|c|c|}
\hline \multirow[b]{2}{*}{ Measure } & \multicolumn{3}{|l|}{ Ipsilateral } & \multicolumn{3}{|c|}{ Contralateral } \\
\hline & Prelesion & Postlesion & Post/pre (\%) & Prelesion & Postlesion & Post/pre (\%) \\
\hline \multicolumn{7}{|l|}{ L4 DLF lesions } \\
\hline Background & $38 \pm 7$ & $49 \pm 5$ & 129 & $35 \pm 7$ & $48 \pm 5$ & 137 \\
\hline Dynamic & $376 \pm 52$ & $509 \pm 242^{*}$ & 135 & $374 \pm 40$ & $295 \pm 18$ & 79 \\
\hline Static & $265 \pm 39$ & $396 \pm 122^{*}$ & 149 & $256 \pm 39$ & $198 \pm 10$ & 77 \\
\hline \multicolumn{7}{|c|}{ T13-L3 DLF lesions } \\
\hline Background & $54 \pm 7$ & $128 \pm 52^{*}$ & 237 & $38 \pm 5$ & $42 \pm 2$ & 111 \\
\hline Dynamic & $466 \pm 33$ & $795 \pm 122^{*}$ & 171 & $433 \pm 46$ & $373 \pm 11$ & 86 \\
\hline Static & $376 \pm 29$ & $652 \pm 122^{*}$ & 173 & $319 \pm 31$ & $281 \pm 9$ & 88 \\
\hline
\end{tabular}

Reflex activity evoked by $30^{\circ}$ dorsiflexion at $60^{\circ} / \mathrm{sec}$ from foot-tibial angles of $120^{\circ}$ (T13-L3 lesions) or $143^{\circ}$ (L4 lesions).

*Statistical significance at $p<0.05$, using two-tailed $t$ tests.

tralateral limb flexed. When the investigator applied force to the plantar surface of the foot, the knees flexed readily during preoperative testing (average ratings of 2.1 and 2.3), but postoperatively the ipsilateral knee remained extended (average rating of 3.4). The score for resistance to flexion of the hindlimb was reduced on the contralateral side (rating of 1.6), confirming results obtained with the quantitative stretch reflex analysis.

Postoperative attempts to elicit clonus by rapid dorsiflexion of the ankle or repeated cutaneous stimulation did not produce repetitive motor responses. The Babinski sign and reflex were not evoked in the normal animal, but either or both could be observed postoperatively. During preoperative testing of the positive support response, the hindlimbs supported weight after contact with a surface (rating of 1.5). However, the DLF lesions produced dysmetric hindlimb responses ipsilaterally, evident as hypermetric extension (rating of 2.4) and a failure to retract the limb after surface contact. Quantitative examination of the positive support reaction from videotapes supported the subjective results. Preoperatively, the limb ipsilateral to a subsequent lesion landed an average of $1.0 \pm 0.3 \mathrm{~cm}$ behind the contralateral paw. Postoperatively, a pronounced hypermetric extension was evident, and the ipsilateral limb landed $2.8 \pm 0.5 \mathrm{~cm}$ forward of the contralateral limb.

Relationships between the results of clinical assessments and the quantitative stretch reflex data after T13-L3 DLF lesions were evaluated by Spearman rank correlational analysis. Over the first six postoperative weeks, significant correlations were identified for: (1) the evoked Babinski reflex and dynamic stretch reflex amplitude $(r=0.60)$, and (2) the positive support response and static amplitude $(r=0.68)$. However, these correlations were not maintained over the 5 months of postoperative testing.

Construction and evaluation of a sum scale identified measures of hindlimb function that reliably discriminated between the preoperative and early postoperative periods of testing. The statistic adopted was Cronbach's $\alpha$ coefficient (Nunally, 1970), where a value of 1 represents the condition in which items are perfectly reliable and measure the same effect. The contribution of each item was checked by eliminating it from the sum scale. The sum scale that included all 14 measures from clinical examination and stretch reflex testing $(\alpha=0.62)$ was improved most when only dynamic and static amplitude were retained $(\alpha=0.98)$. The optimal sum scale based solely on subjective clinical assessments included the rating scales for extensor posture and resistance to hindlimb flexion $(\alpha=0.89)$.

\section{DISCUSSION}

Quantitative analyses of stretch reflexes are provided, using natural stimulus conditions and providing longitudinal analyses that establish the reliability of the testing method and assess the time course of functional pathology after SCI (Wiesendanger, 1985; Little, 1986; Goldberger et al., 1990; Burke, 1993). Studying reflexes in awake animals avoids a powerful attenuation of spinal reflexes by anesthesia or disruption of descending modulation by decerebration.

Stretch responses were obtained under conditions of limited weight bearing, when the extensor muscles for the ankle were partially loaded. The animals were adapted to frequent passive stretching of the triceps surae muscles to permit comparisons with tests of passive stretch reflexes of humans, who can be instructed to relax and permit passive movement. Different characterizations of spastic patients result from reflex activation during active or passive movement (Dietz et al., 1993; Thilmann, 1993).

Bilateral reflex recordings were obtained before and after a unilateral lesion to establish whether the effects of the lesion were unilateral (comparing preoperative and postoperative reflexes for each hindlimb). Postoperative increases in reflex force were strictly ipsilateral and persisted for more than 1 year after lesions of the dorsolateral funiculus at levels ranging from T13 to L3. Slight contralateral decreases in resistance to stretch were detected, which is consistent with reciprocal effects that have been observed for human hemiparetic upper limb stretch reflexes (Thilmann et al., 1990).

It is possible that an animal would compensate for the effects of a unilateral lesion by shifting the weight consistently to one side, even though the restraint system was designed to maintain the cats in a centered position. Such a postural adaptation would produce asymmetrical background forces. Therefore, comparisons of preoperative and postoperative trials with matched background forces were made for each animal, and significant ipsilateral hyperreflexia was demonstrated. In addition, transient hyperreflexia was observed after the small L4 lesions, and postoperative background forces were comparable for the ipsilateral and contralateral limbs of these animals. Thus, postoperative hyperreflexia in the ipsilateral limb was not related to a postural adaptation.

Clinical examinations of hindlimb tone and reflexes were conducted to compare results of these commonly used measures with quantitative assessments of stretch reflexes in the same animals. 


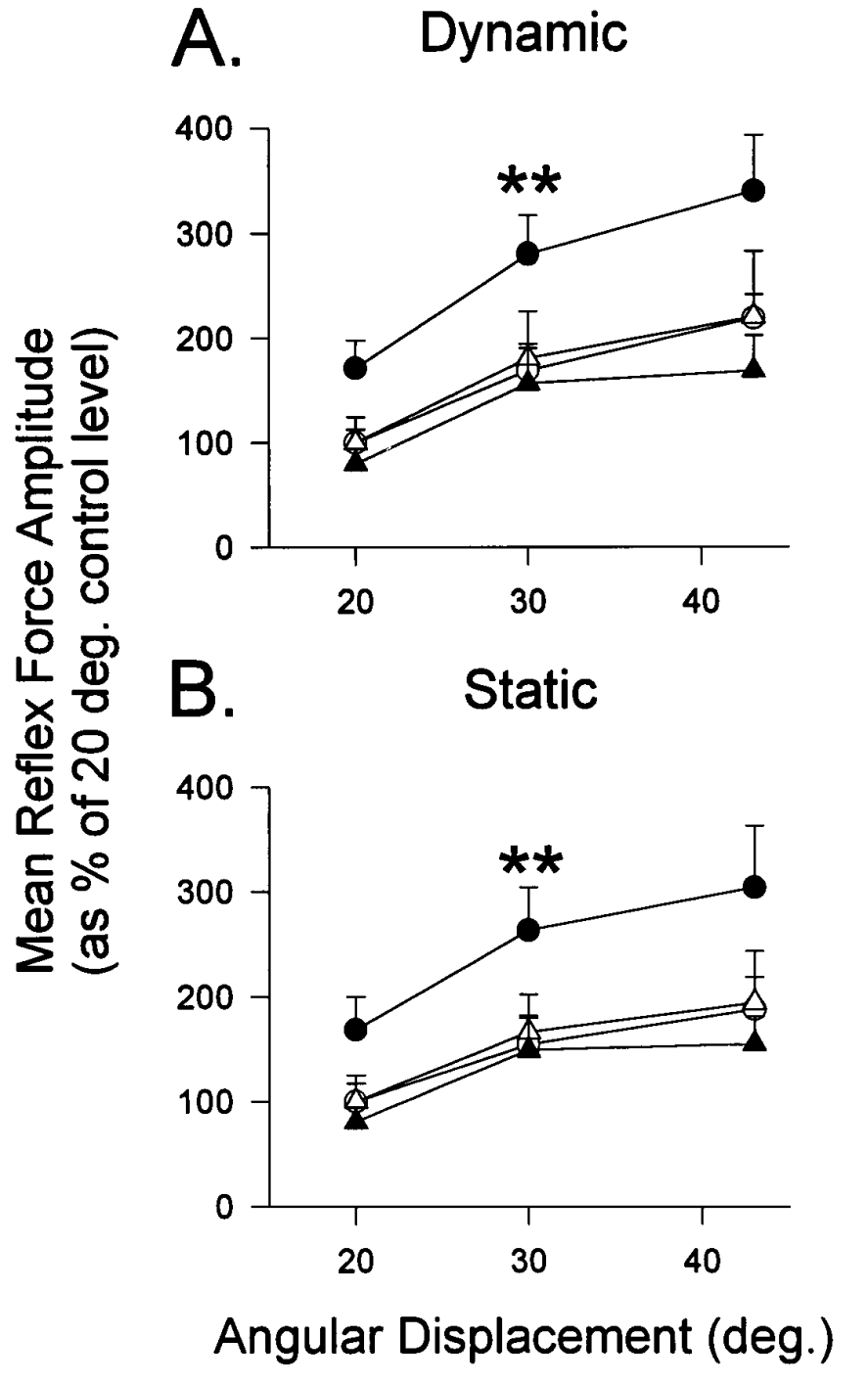

Figure 5. Mean dynamic $(A)$ and static $(B)$ reflex force evoked by three angles of displacement during 26 weeks of testing after T13-L3 lesions of the DLF. The postoperative responses were normalized as percentages of the preoperative responses of the same leg to $20^{\circ}$ dorsiflexion: ipsilateral (circles), contralateral (triangles), preoperative (open symbols), and postoperative (closed symbols). For statistical comparison of postoperative and preoperative functions, asterisks indicate statistical significance $(p<0.01)$ for ipsilateral elevations of dynamic and static force. The slope of the relationship between reflex force and angular displacement increased postoperatively $\left(A, 5.1-7.2 \% /^{\circ} ; B, 3.8-5.8 \% /^{\circ}\right)$.

One goal of these comparisons was to identify tests that reliably detected the presence of DLF lesions. The most reliable sum scale for detecting DLF lesion effects used only the quantitative measures of dynamic and static reflex amplitude. The subjective tests did not improve discriminatory power and thus can be regarded as supplementary but not as substitutes for quantitative reflex testing. This conclusion holds particularly for the long-term effects of DLF lesions, because correlative relationships between the qualitative and quantitative results were not significant or were not maintained over months of testing, even though the effects on stretch reflex force were sustained.

\section{EMG activity}

Resistance to dorsiflexion correlated significantly and positively with total EMG activity (SOL plus MG) for both preoperative and

\section{A. L4 Lesions}

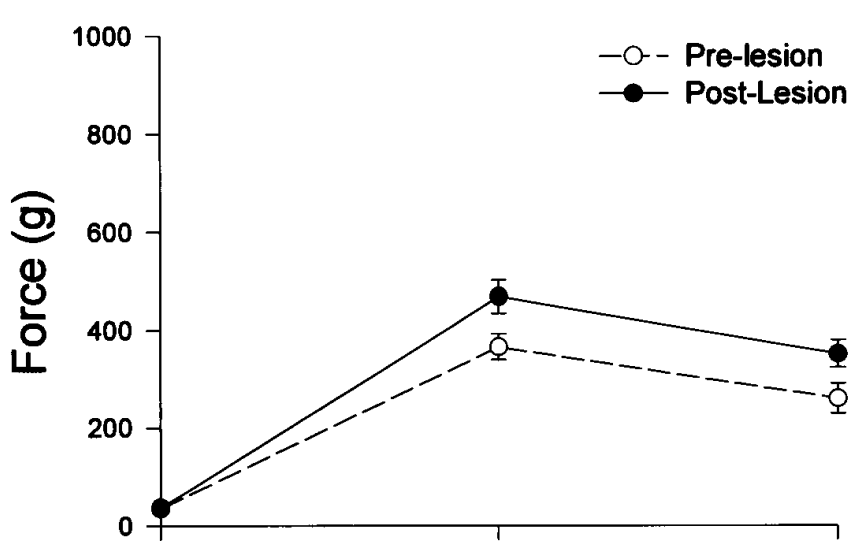

\section{B. T13-L3 Lesions}

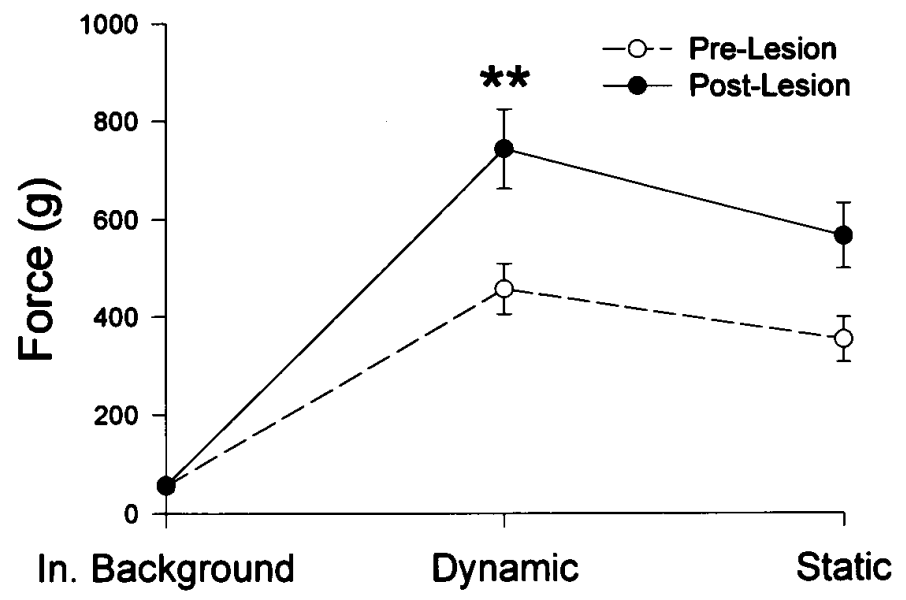

Figure 6. Ipsilateral dynamic and static reflex force on trials matched (within 10\%) for background forces before and after DLF lesions. Averaged postoperative forces obtained from 6 weeks of testing animals with L4 lesions $(A)$ and from 26 weeks of testing animals with T13-L3 lesions (B). ${ }^{* *} p<0.01$.

postoperative measurements of the dynamic and static components of stretch reflexes. Thus, the postoperative increases in reflex force were not likely the result of increased mechanical resistance of the muscles to stretch.

\section{Velocity sensitivity and dynamic index}

In formal tests for velocity dependence of the postoperative reflex changes, DLF lesions between T13 and L3 (but not at L4) produced a greater increase in resistance to dorsiflexion at $60 \% \mathrm{sec}$ compared with $10^{\circ} / \mathrm{sec}$. In addition, a preferential increase in dynamic versus static reflex force was evident as an elevated dynamic index. The velocity-dependent increase in dynamic reflex force and the elevated dynamic index were observed when background forces were matched for preoperative and postoperative testing. The velocity sensitivity of dynamic force was accompanied by equivalent increases in SOL muscle responses to dorsiflexion, and the responses arose from significant levels of SOL background activity but were unrelated to the amount of background activation of SOL.

The velocity dependence of increased stretch reflexes after neural injury is controversial, with evidence for (Thilmann et 
Table 2. Correlations between reflex force and EMG activity before and after ipsilateral DLF lesions.

\begin{tabular}{|c|c|c|c|c|c|c|c|}
\hline \multirow[b]{2}{*}{ Reflex parameter } & \multirow{2}{*}{$\begin{array}{l}\text { Force } \\
(\mathrm{gm})\end{array}$} & \multicolumn{2}{|c|}{ Soleus EMG } & \multicolumn{2}{|c|}{ MG EMG } & \multicolumn{2}{|c|}{ Total EMG } \\
\hline & & $\mu \mathrm{V}$ & $r$ & $\mu \mathrm{V}$ & $r$ & $\mu \mathrm{V}$ & $r$ \\
\hline \multicolumn{8}{|l|}{ Prelesion control } \\
\hline Background force & $54 \pm 7$ & $18 \pm 2$ & $0.43^{*}$ & $13 \pm 2$ & $0.56^{*}$ & $32 \pm 3$ & $0.54 *$ \\
\hline Dynamic amplitude & $466 \pm 33$ & $60 \pm 5$ & $0.61^{*}$ & $64 \pm 10$ & $0.81^{*}$ & $130 \pm 13$ & $0.88^{*}$ \\
\hline Static amplitude & $376 \pm 29$ & $47 \pm 5$ & $0.44^{*}$ & $43 \pm 7$ & $0.81^{*}$ & $98 \pm 9$ & $0.83^{*}$ \\
\hline \multicolumn{8}{|l|}{ T13-L3 DLF lesion } \\
\hline Background force & $134 \pm 19$ & $26 \pm 6$ & $0.37^{*}$ & $24 \pm 6$ & 0.58 & $50 \pm 11$ & 0.54 \\
\hline Dynamic amplitude & $808 \pm 50$ & $82 \pm 7$ & $0.56^{*}$ & $78 \pm 17$ & $0.94 *$ & $175 \pm 23$ & $0.92 *$ \\
\hline Static amplitude & $665 \pm 44$ & $64 \pm 8$ & $0.44 *$ & $59 \pm 13$ & $0.96^{*}$ & $128 \pm 18$ & $0.94^{*}$ \\
\hline
\end{tabular}

EMG activity is shown for MG, SOL, and their sum (total), averaged over 6 week prelesion and postlesion periods. *Statistical significance at $p<0.05 ; n=4$.

\section{Cat \#3}

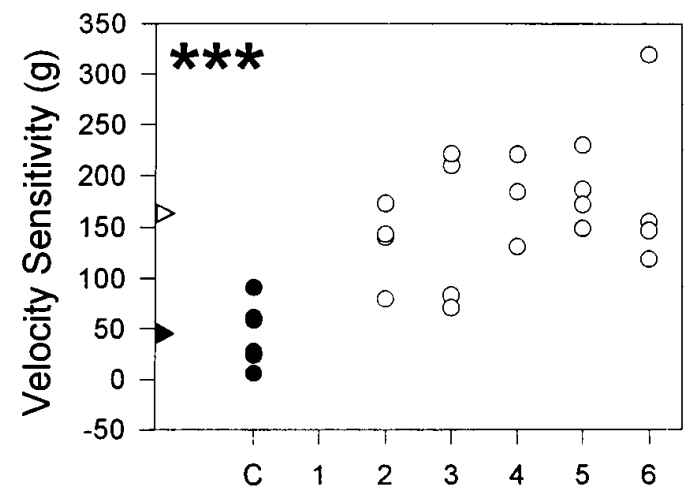

Cat \#5

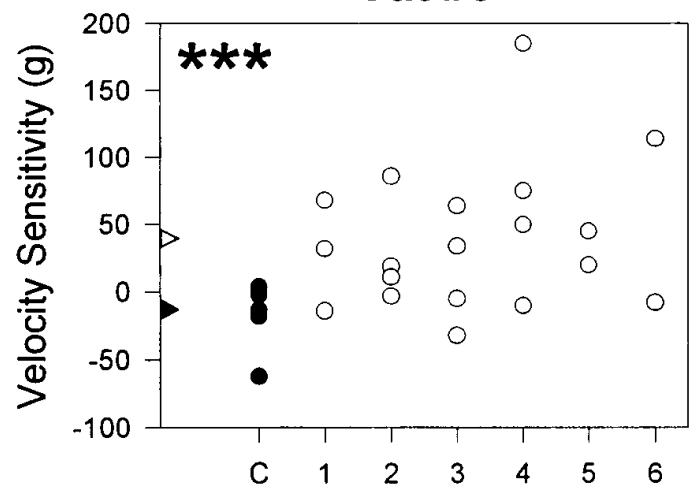

Cat \#4

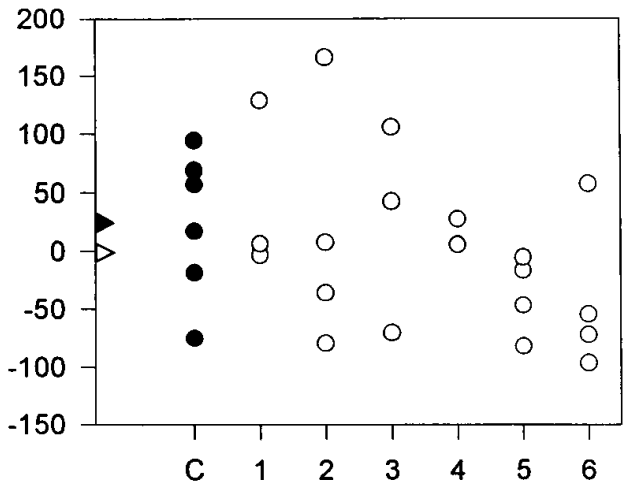

Cat \#6

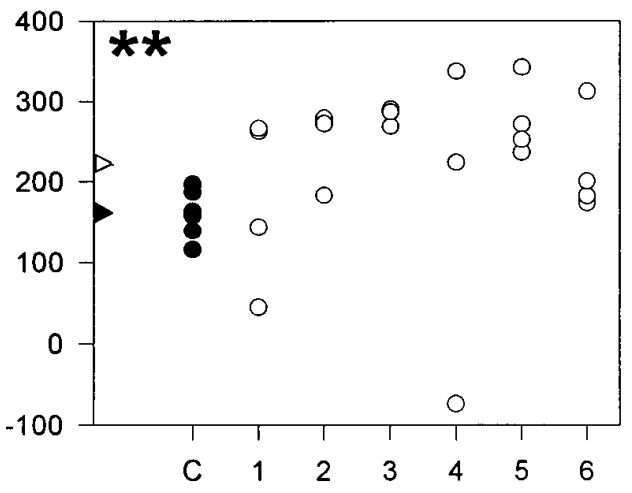

Figure 7. Scatter plots of ipsilateral dynamic velocity sensitivity recorded from cats 3-6 before and after DLF lesions at the T13-L3 level. Velocity sensitivity is represented as differences between responses to 10 and $60^{\circ} / \mathrm{sec}$ dorsiflexions during randomly selected sessions $(C, 1-6)$ using a $30^{\circ}$ displacement from a foot-tibial angle of $120^{\circ}$. Filled circles represent control (preoperative) responses $(C$ ), and open circles indicate postoperative recordings. Statistical analysis was performed using one-tailed $t$ tests: Cat \#6, ${ }^{*} t=2.43$; df $=24 ; p<0.01 ; C a t \# 3$, ***t ${ }^{*}=5.77 ; \mathrm{df}=25 ; p<0.001 ;$ Cat $\# 5, * * * t=3.46 ; \mathrm{df}=23 ; p<0.001$.

al., 1991) and against (Powers et al., 1988) this phenomenon as characteristic of spasticity. Testing of passive stretch reflexes, as in the present study, may be a necessary condition for observing increased velocity sensitivity (Lance et al., 1966; Herman, 1970; Burke et al., 1971) and an elevated dynamic index (Herman, 1970; Ashby and Burke, 1971) as a result of CNS lesions. However, it is clear that hyperreflexia after interruption of the DLF did not result entirely from an increase in velocity sensitivity. It was apparent at low rates of dorsiflexion and was associated with exaggerated extensor tone.

\section{Relationships of lesion extent and location to effects on stretch reflexes}

Dorsal hemisection produces exaggerated spinal reflexes, as evidenced by acute recordings from decerebrate cats (Rymer et al., 1979; Powers and Rymer, 1988; Carp et al., 1991). The present study complements these findings by demonstrating a unilateral hyperreflexia in awake animals after lesions that involve the dorsolateral tip of the lateral column, with generally minor involvement of the ipsilateral dorsal column. The more 
A.

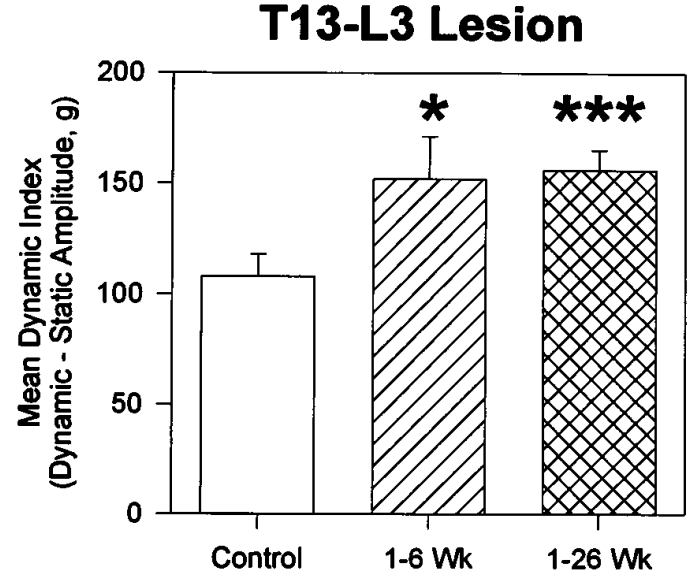

B.

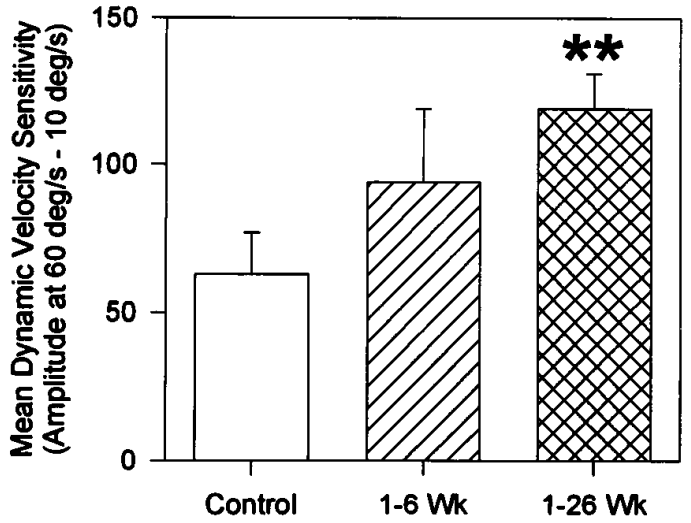

L4 Lesion
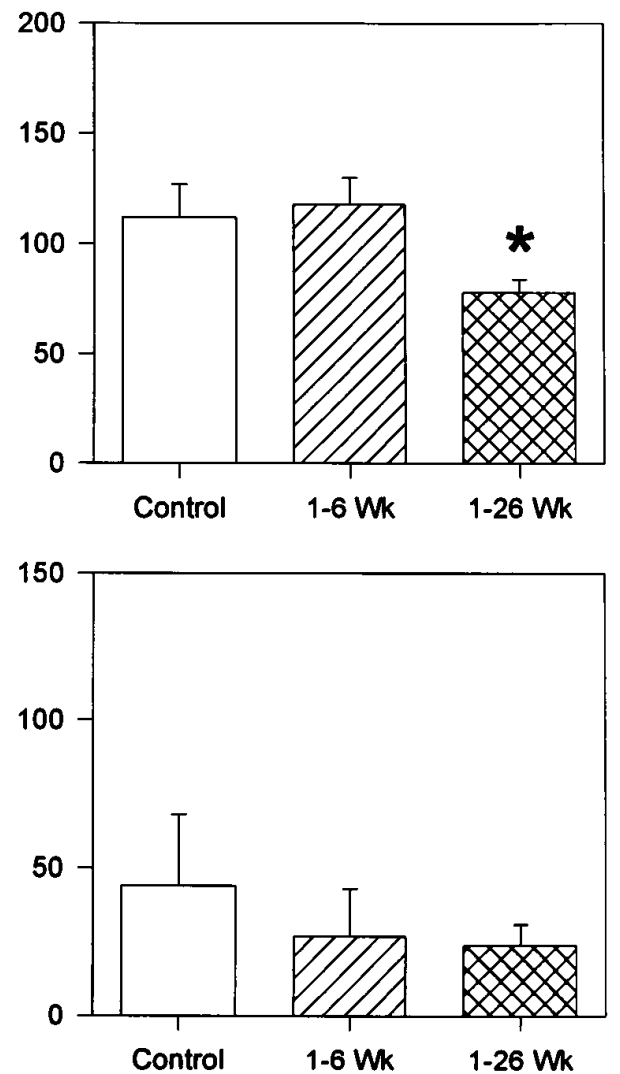

Figure 8. Mean dynamic index $(A)$ and velocity sensitivity $(B)$ of reflexes evoked before and after T13-L3 (left column) or L4 (right column) lesions. Reflexes evoked by $30^{\circ}$ displacement from a foot-tibial angle of either $120^{\circ}$ (left column) or $143^{\circ}$ (right column) at $60^{\circ} / \mathrm{sec}$ for calculation of dynamic index $(A)$ and at 10 and $60^{\circ} / \mathrm{sec}$ for velocity sensitivity $(B)$. Statistical analysis was performed using one-tailed $t$ tests: $* p<0.05 ; \mathrm{df}=40(A) ; * p<0.01 ; \mathrm{df}=$ $102 ; * * * p<0.001 ; \mathrm{df}=111 ; * p<0.05 ; \mathrm{df}=46(B)$.

effective lesions at T13-L3 involved a slightly greater proportion of the DLF than the lesions at L4. Thus, lesion extent was an important determinant of the magnitude and duration of postoperative hyperreflexia. Proximity to hindlimb motoneuronal pools was not a critical factor, as it can be for lateral hemisection in anesthetized preparations (Nelson and Mendell, 1979; Carter et al., 1991).

Interruption of the corticospinal tract could contribute to hyperreflexia after interruption of the DLF (Wagley, 1945; Bucy et al., 1964; Woolsey, 1971). However, the lesions in the present study did not extend throughout the location of the corticospinal pathway. Also, the Babinski sign and reflex that are presumed to result from corticospinal damage (Bucy et al., 1964) were only observed occasionally. Release of the Babinski reflex has been regarded as an example of an exaggerated flexion reflex (Walshe, 1956) that is not always associated with increased flexor reflex activity (Van Gijn, 1978).

Partial involvement of the dorsal column could have contributed to the observed result. Enhanced monosynaptic EPSPs have been observed after DC lesions (Decima and Morales, 1983; but see Nelson and Mendell 1979), either as a result of pruning ascending collaterals of Ia afferents to the dorsal horn or from interrupting descending projections in the dorsal columns (Burton and Loewy, 1977; Bromberg et al., 1981; Enevoldson and Gordon, 1984). However, the lesions at T13-L3 produced only minor effects on: (1) collaterals of hindlimb Ia afferents that project in the dorsal columns to the lower thoracic spinal cord (Fern et al., 1988), or (2) other afferents from L7 and S1 that are located near the midline in the dorsal columns (Ishizuka et al., 1979). Furthermore, descending projections in the dorsal column would have been affected little, if at all, by the lesions in animals 3-5.

It is likely that the positive support reaction in the normal cat is mediated by ascending and descending pathways in the lateral funiculus, to and from the lateral reticular nucleus, and to a lesser extent by vestibulospinal systems. Unilateral lesions of the lateral reticular nucleus produce a postural deficit and ipsilateral hypertonia of the hindlimb extensor muscles during the positive support test (Corvaja et al., 1977). In the present study, both qualitative and quantitative positive support tests revealed ipsilateral dysmetria and extension of the ipsilateral hindlimb. Also, ratings of resting extensor tone and resistance of the hindlimb to flexion revealed an ipsilateral hypertonia and were identified as the best combination of subjective tests for the DLF lesion effect. Thus, the functional effects of the T13-L3 spinal lesions seem to result from interruption of reticulospinal pathways that course through the dorsolateral funiculus (Nathan and Smith, 1955; Aggelopoulos et al., 1966; Engberg et al., 1968; Peterson et al., 1975; Jeneskog and Johansson, 1977; Kuypers, 1981).

The descending reticulospinal pathways in the DLF have been considered to be inhibitory for both muscular and cutaneous reflexes (Holmqvist and Lundberg, 1959; Sandkuhler et 
Table 3. Mean values of scores on clinical tests, before and after T13L3 spinal lesions, evaluated over a 26 week period

\begin{tabular}{|c|c|c|c|c|}
\hline Subjective measure & Control & $\begin{array}{l}\text { Post- } \\
\text { lesion }\end{array}$ & $U$ & $p$ \\
\hline \multicolumn{5}{|l|}{ Ashworth scale } \\
\hline Ankle flexion (ipsilateral) & 1.3 & 2.1 & 364 & $<0.05$ \\
\hline Ankle flexion (contralateral) & 1.0 & 0.9 & 509 & - \\
\hline Knee flexion (ipsilateral) & 1.2 & 2.0 & 386 & $<0.05$ \\
\hline Knee flexion (contralateral) & 0.9 & 0.7 & 437 & - \\
\hline Hip flexion (ipsilateral) & 0.7 & 0.9 & 421 & - \\
\hline Hip flexion (contralateral) & 0.9 & 0.6 & 353 & - \\
\hline \multicolumn{5}{|l|}{ Extensor tone } \\
\hline Tonic extension (ipsilateral) & 2.9 & 3.5 & 437 & - \\
\hline Tonic extension (contralateral) & 3.2 & 2.7 & 446 & - \\
\hline Hindlimb flexion (ipsilateral) & 2.1 & 3.4 & 294 & $<0.001$ \\
\hline Hindlimb flexion (contralateral) & 2.3 & 1.6 & 420 & $<0.05$ \\
\hline \multicolumn{5}{|l|}{ Babinski sign } \\
\hline Tonic Babinski (ipsilateral) & 0.6 & 0.8 & 392 & - \\
\hline Tonic Babinski (contralateral) & 0.7 & 0.2 & 304 & $<0.001$ \\
\hline Evoked Babinski (ipsilateral) & 0.0 & 0.2 & 384 & $<0.05$ \\
\hline Evoked Babinski (contralateral) & 0.0 & 0.0 & 444 & - \\
\hline \multicolumn{5}{|l|}{ Positive support test } \\
\hline $\begin{array}{l}\text { Positive support response } \\
\text { (ipsilateral) }\end{array}$ & 1.5 & 2.4 & 238 & $<0.001$ \\
\hline $\begin{array}{l}\text { Positive support response } \\
\text { (contralateral) }\end{array}$ & 1.7 & 1.6 & 524 & - \\
\hline
\end{tabular}

Statistical analysis was performed using the Mann-Whitney test.

al., 1987; Pubols et al., 1991), although disinhibitory mechanisms have also been shown for group Ib and slower afferents (Engberg et al., 1968; Grillner, 1970; Iles et al., 1989). After interruption of DLF axons, descending modulatory influences from pathways in the ventrolateral funiculus are expected to predominate, and these have been characterized as both facilitatory and inhibitory (Jankowska et al., 1968; Kuypers, 1981; White et al., 1991; Brown, 1994; Liu et al., 1995). Included within the spared ventrolateral funiculus are reticulospinal and vestibulospinal pathways responsible for maintenance of tonus in the hindlimb musculature (Schreiner et al., 1949; Peterson et al., 1975; Peterson, 1979).

\section{Defining a model of spasticity}

A distinction should be made between a definition of spasticity that is restricted to a velocity-dependent exaggeration of stretch reflexes (Lance, 1980) and the more general consequences of upper motoneuron lesions that are sometimes referred to as the spastic syndrome (Dimitrijevic and Nathan, 1967; Landau, 1974; Ashby et al., 1987). Characteristics of the spastic syndrome are: (1) increased tone and the clasp-knife phenomenon (Burke et al., 1970), (2) a gradual development of hyperreflexia over time after spinal injury (Putnam, 1940; Kuhn, 1950; Liu et al., 1966; Meinck et al., 1985; Ashby and McCrea, 1987; Thilmann et al., 1991), (3) generalization of stretch hyperreflexia to other muscles and enhancement of cutaneous reflexes to the extent that mass reflexes can be elicited (Kuhn, 1950; Dimitrijevic and Nathan, 1967; Landau, 1974; Meinck et al., 1985), and (4) appearance of the Babinski reflex and clonus (Dimitrijevic and Nathan, 1967; Burke, 1988).

After DLF lesions there were reliable indications of enhanced extensor tone, but clasp-knife responses were not eval- uated systematically. The Babinski sign and reflex were observed occasionally, but there was no evidence of clonus or flexor spasms. The hyperactivity of stretch reflexes did not develop gradually from an initial postoperative hyporeflexia, and there was no evidence of a generalized increase in flexor reflex activity. Thus, the DLF lesion model of spinal cord injury produced a mild spasticity (Colter et al., 1988) but not the complete spastic syndrome. Possibly a substantial deprivation of descending input to spinal motoneurons (by large spinal lesions) attenuates responsivity to segmental inputs for weeks before the spastic syndrome develops, with segmental reorganization of inputs to interneurons and motoneurons (Murray and Goldberger, 1974; Helgren and Goldberger, 1993; Hochman and McCrea, 1994).

\section{REFERENCES}

Aggelopoulos NC, Burton MJ, Clarke RW, Edgley SA (1966) Characterization of a descending system that enables crossed group II inhibitory reflex pathways in the cat spinal cord. J Neurosci $16: 723-729$.

Aoki M, Mori S, Fujimori B (1976) Exaggeration of knee-jerk following spinal hemisection in monkeys. Brain Res 107:471-485.

Ashby P, Burke D (1971) Stretch reflexes in upper limb of spastic man. J Neurol Neurosurg Psychiatry 34:765-771.

Ashby P, McCrea DA (1987) Neurophysiology of spinal spasticity. In: Handbook of the spinal cord (Davidoff RA, ed), pp 119-143. New York: Dekker.

Ashby P, Mailis A, Hunter J (1987) The evaluation of "spasticity." Can J Neurol Sci 14:497-500.

Ashworth B (1964) Preliminary trial of carispodol in multiple sclerosis. Practitioner 192:540-542.

Bohannon RW, Smith MB (1987) Interrater reliability of a modified Ashworth scale of muscle spasticity. Phys Ther 67:206-207.

Bromberg MB, Burnham JA, Towe AL (1981) Doubly projecting neurons of the dorsal column nuclei. Neurosci Lett 25:215-220.

Brown P (1994) Pathophysiology of spasticity. J Neurol Neurosurg Psychiatry 57:773-777.

Bucy PC, Keplinger JE, Siqueira EB (1964) Destruction of the "pyramidal tract" in man. J Neurosurg 21:285-298.

Burke DJ (1988) Spasticity as an adaptation to pyramidal tract injury. In: Functional recovery in neurological disease, advances in neurology, Vol 47 (Waxman SG, ed), pp 401-423. New York: Raven.

Burke DJ (1993) Spinal pathophysiology: animal models. Discussion summary. In: Spasticity: mechanisms and management (Thilmann AF, Burke DJ, Rymer WZ, eds), pp 231-236. Berlin: Springer.

Burke DJ, Gillies JD, Lance JW (1970) The quadriceps stretch reflex in human spasticity. J Neurol Neurosurg Psychiatry 33:216-223.

Burke DJ, Andrews CJ, Gillies JD (1971) Reflex response to sinusoidal stretch in spastic man. Brain 94:455-470.

Burke DJ, Knowles L, Andrews C, Ashby P (1972) Spasticity, decerebrate rigidity and the clasp-knife phenomenon: an experimental study in the cat. Brain 95:31-48.

Burton H, Loewy AD (1977) Projections to the spinal cord from medullary somatosensory relay nuclei. J Comp Neurol 173:773-792.

Carp JS, Powers RK, Rymer WZ (1991) Alterations in motoneuron properties induced by acute dorsal spinal hemisection in the decerebrate cat. Exp Brain Res 83:539-548.

Carter RL, Ritz LA, Shank CP, Scott EW, Sypert GW (1991) Correlative electrophysiological and behavioral evaluation following L5 lesions in the cat: a model of spasticity. Exp Neurol 114:206-215.

Cavallari P, Pettersson LG (1989) Tonic suppression of reflex transmission in low spinal cats. Exp Brain Res 77:201-212.

Colter S, Rucker NC (1988) Acute injury to the central nervous system. Vet Clin North Am Small Anim Pract 18:3:545-563.

Corvaja N, Grofova I, Pompeiano O, Walberg F (1977) The lateral reticular nucleus in the cat-II. Effects of lateral reticular lesions on posture and reflex movements. Neuroscience 2:929-943.

Decima EE, Morales FR (1983) Long-lasting facilitation of a monosynaptic pathway as a result of "partial" axotomy of its presynaptic elements. Exp Neurol 79:532-551. 
Dietz V, Ibrahim IK, Trippel M, Berger W (1993) Spastic paresis: reflex activity and muscle tone in elbow muscles during passive and active motor tasks. In: Spasticity: mechanisms and management (Thilmann AF, Burke DJ, Rymer WZ, eds), pp 251-265. Berlin: Springer.

Dimitrijevic MR, Nathan PW (1967) Studies of spasticity in man. I. Some features of spasticity. Brain 90:1-30.

Enevoldson TP, Gordon G (1984) Spinally projecting neurons in the dorsal column nuclei: distribution, dendritic trees and axonal projections. Exp Brain Res 54:538-550.

Engberg I, Lundberg A, Ryall RW (1968) Reticulospinal inhibition of transmission in reflex pathways. J Physiol (Lond) 194:201-223.

Fern R, Harrison PJ, Riddell JS (1988) The dorsal column projection of muscle afferent fibres from the cat hindlimb. J Physiol (Lond) 401:97-113.

Fujimori B, Kato M, Matsushima S, Mori S, Shimamura M (1966) Studies on the mechanism of spasticity following spinal hemisection in the cat. In: Muscular afferents and motor control, Nobel symposium I (Granit R, ed), pp 397-413. Uppsala: Almquist and Wiskell.

García-Larrea L, Charles N, Sindou M, Mauguière F (1993) Flexion reflexes following anterolateral cordotomy in man: dissociation between pain sensation and nociceptive reflex RIII. Pain 55:139-149.

Goldberger ME, Bregman BS, Vierck Jr CJ, Brown M (1990) Criteria for assessing recovery of function after spinal cord injury: behavioral methods. Exp Neurol 107:113-117.

Grillner S (1970) Is the tonic stretch reflex dependent upon group II excitation? Acta Physiol Scand 78:431-432.

Heckman CJ (1994) Alterations in synaptic input to motoneurons during partial spinal cord injury. Med Sci Sports Exerc 26:1480-1490.

Helgren ME, Goldberger ME (1993) The recovery of postural reflexes and locomotion following low thoracic hemisection in adult cats in volves compensation by undamaged primary afferent pathways. Exp Neurol 123:17-34.

Herman R (1970) Myotatic reflex: clinicophysiological aspects of spasticity and contraction. Brain 98:273-312.

Hochman S, McCrea DA (1994) Effects of chronic spinalization on ankle extensor motoneurons III. Composite Ia EPSPs in motoneurons separated into motor unit types. J Neurophysiol 71:1480-1490.

Hoffer JA, Leonard TR, Cleland CL, Sinkjaer T (1990) Segmental reflex action in normal and decerebrate cats. J Neurophysiol 64:1611-1624.

Holmqvist B, Lundberg A (1959) On the organization of the supraspinal inhibitory control of interneurones of various spinal reflex arcs. Arch Ital Biol 97:340-356.

Hultborn H, Malmsten J (1983a) Changes in segmental reflexes following chronic spinal cord hemisection in the cat. I. Increased monosynaptic and polysynaptic ventral root discharges. Acta Physiol Scand 119:405-422.

Hultborn H, Malmsten J (1983b) Changes in segmental reflexes following chronic spinal cord hemisection in the cat. II. Conditioned monosynaptic test reflexes. Acta Physiol Scand 119:423-433.

Iles JF, Jack JB, Kullmann DM, Roberts RC (1989) The effects of lesions on autogenetic inhibition in the decerebrate cat. J Physiol (Lond) 419:611-625.

Ishizuka NH, Mannen T, Hongo T, Sasaki S (1979) Trajectory of group Ia afferent fibers stained with horseradish peroxidase in the lumbosacral spinal cord of the cat: three dimensional reconstructions from serial sections. J Comp Neurol 186:189-212.

Jankowska E, Lund E, Lundberg A, Pompeiano O (1968) Inhibitory effects evoked through ventral reticulospinal pathways. Arch Ital Biol 106:124-140.

Jeneskog T, Johansson H (1977) The rubro-bulbospinal path. A descending system known to influence dynamic fusimotor neurones and its interaction with distal cutaneous afferents in the control of flexor reflex afferent pathways. Exp Brain Res 27:161-179.

Katz RT, Rymer WZ (1989) Spastic hypertonia: mechanisms and measurement. Arch Phys Med Rehabil 70:144-155.

Kuhn RA (1950) Functional capacity of the isolated human spinal cord. Brain 73:1-51.

Kuypers HGJM (1981) Anatomy of the descending pathways. In: Handbook of physiology, Sect 1, Vol 2 (Brooks VB, ed), pp 597-666. Baltimore: Williams \& Wilkins.

Lance JW (1980) Symposium synopsis. In: Spasticity: disordered motor control (Feldman RG, Young RR, Koella WP, eds), pp 485-494. Chicago: Year Book.
Lance JW, De Gail P, Neilson PD (1966) Tonic and phasic spinal cord mechanisms in man. J Neurol Neurosurg Psychiatry 29:535-544.

Landau WM (1974) Spasticity: the fable of a neurological demon and the emperor's new therapy. Arch Neurol 31:217-219.

Lee WA, Boughton A, Rymer WZ (1987) Absence of stretch reflex gain enhancement in voluntarily activated spastic muscle. Exp Neurol 98:317-335.

Little JW (1986) Serial recording of reflexes after feline spinal cord transection. Exp Neurol 93:510-521.

Liu CN, Chambers WW, McCouch GP (1966) Reflexes in the spinal monkey. Brain 89:349-358.

Liu R-H, Fung SJ, Reddy VK, Barnes CD (1995) Localization of glutamatergic neurons in the dorsolateral pontine tegmentum projecting to the spinal cord of the cat with a proposed role of glutamate on lumbar motoneuron activity. Neuroscience 64:193-208.

Loeb GE, Gans C (1986) Electromyography for experimentalists. Chicago: University of Chicago.

Malmsten J (1983) Time course of segmental reflex changes after chronic spinal cord hemisection in the rat. Acta Physiol Scand 119:435-443.

Meinck H-M, Benecke R, Conrad B (1985) Spasticity and flexor reflex. In: Clinical neurophysiology in spasticity (Delwaide PJ, Young RR, eds), pp 42-54. New York: Elsevier.

Miller S (1993) Reflex disturbances in spasticity: movement studies; discussion summary. In: Spasticity: mechanisms and management (Thilmann AF, Burke DJ, Rymer WZ, eds), pp 266-269. Berlin: Springer.

Murray M, Goldberger ME (1974) Restitution of function and collateral sprouting in the cat spinal cord: the partially hemisected animal. J Comp Neurol 158:19-36.

Nathan PW (1994) Effects on movement of surgical incisions into the human spinal cord. Brain 117:337-346.

Nathan PW, Smith MC (1955) Long descending tracts in man. I. Review of present knowledge. Brain 78:248-303.

National Institutes of Health (1991) Preparation and maintenance of higher mammals during neuroscience experiments, National Institutes of Health publication 91-3207. Bethesda, MD: National Institutes of Health.

Nelson SG, Mendell LM (1979) Enhancement in Ia-motoneuron synaptic transmission caudal to chronic spinal cord transection. J Neurophsiol 42:642-654.

Nunally JC (1970) Introduction to psychological measurement. New York: McGraw-Hill.

Peterson BW (1979) Reticulospinal projections to spinal motor nuclei. Annu Rev Physiol 41:127-140.

Peterson BW, Maunz RA, Pitts NG, Mackel RG (1975) Patterns of projection and branching of reticulospinal neurons. Exp Brain Res 23:333-351.

Powers RK, Rymer WZ (1988) Effects of acute dorsal spinal hemisection on motoneuron discharge in the medial gastrocnemius of the decerebrate cat. J Neurophysiol 59:1540-1556.

Powers RK, Campbell DL, Rymer WZ (1988) Stretch reflex dynamics in spastic elbow flexor muscles. Ann Neurol 25:32-42.

Pubols LM, Simone DA, Bernau NA, Atkinson JD (1991) Anesthetic blockade of the dorsolateral funiculus enhances evoked activity of spinal cord dorsal horn neurons. J Neurophysiol 66:140-152.

Putnam TJ (1940) Treatment of unilateral paralysis agitans by section of the lateral pyramidal tract. Arch Neurol Psychiatry 44:950-976.

Rymer WZ, Houk JC, Crago PE (1979) Mechanisms of the clasp-knife reflex studied in an animal model. Exp Brain Res 37:93-113.

Sandkuhler J, Maisch B, Zimmermann M (1987) The use of local anaesthetic microinjections to identify central pathways: a quantitative evaluation of the time course and extent of the neuronal block. Brain Res 68:168-178.

Schreiner LM, Lindsley DB, Magoun HW (1949) Role of brain stem facilitatory systems in maintenance of spasticity. J Neurophysiol 12:207-216.

Teasdall RD, Villablanca J, Magladery JW (1965) Reflex responses to muscle stretch in cats with chronic suprasegmental lesions. Bull Johns Hopkins Hosp 116:229-242.

Thilmann AF (1993) Spasticity: history, definitions, and usage of the term. In: Spasticity: mechanisms and management (Thilmann AF, Burke DJ, Rymer WZ, eds), pp 1-7. Berlin: Springer.

Thilmann AF, Fellows SJ, Garms E (1990) Pathological stretch reflexes 
on the "good" side of hemiparetic patients. J Neurol Neurosurg Psychiatry 53:208-214.

Thilmann AF, Fellows SJ, Garms E (1991) The mechanism of spastic muscle hypertonus: variation in relex gain over the time course of spasticity. Brain 114:233-244.

Toft E, Sinkjaer T, Andreassen S, Larsen K (1991) Mechanical and electromyographic responses to stretch of the human ankle extensors. J Neurophysiol 65:1402-1410.

Van Gijn J (1978) The Babinski sign and the pyramidal syndrome. J Neurol Neurosurg Psychiatry 41:865-873.

Vierck Jr CJ (1991) Can mechanisms of central pain be investigated in animal models? In: Pain and central nervous system disease: the central pain syndromes (CPS) (Casey K, ed), pp 129-141. New York: Raven. Vierck Jr CJ, Greenspan JD, Ritz LA (1990) Long-term changes in purposive and reflexive responses to nociceptive stimulation in monkeys following anterolateral chordotomy. J Neurosci 10:2077-2095.

Wagley PF (1945) A study of spasticity and paralysis. Bull Johns Hopkins Hosp 77:218-274.

Walshe F (1956) The Babinski plantar response, its form and its physiological and pathological significance. Brain 79:529-556.

White SR, Fung SJ, Barnes CD (1991) Norepinephrine effects on spinal motoneurons. Prog Brain Res 88:343-350.

Wiesendanger M (1985) Is there an animal model of spasticity? In: Clinical neurophysiology in spasticity (Delwaide PJ, Young RR, eds), pp 1-12. New York: Elsevier.

Woolsey CN (1971) Discussion on experimental hypertonia in the monkey: interruption of pyramidal or pyramidal-extra pyramidal cortical projections. Trans Am Neurol Assoc 96:164-166. 